REVISTA DE DERECHO UNED, NÚM. 15, 2014

\title{
EL CONSENTIMIENTO PARA LA APLICACIÓN DE LAS TÉCNICAS DE REPRODUCCIÓN ASISTIDA Y LA DOBLE MATERNIDAD LEGAL. ANÁLISIS DE LA SENTENCIA DEL TRIBUNAL SUPREMO 740/2013, DE 5 DE DICIEMBRE DE 2013
}

\author{
CONSENT FOR THE APPLICATION OF ASSISTED \\ REPRODUCTION TECHNIQUES AND LEGAL DOUBLE \\ MATERNITY. ANALYSIS OF THE SUPREME COURT'S \\ JUDGMENT 740/2013, OF DECEMBER 5, 2013
}

\section{Alberto Fabar Carnero}

Abogado

Doctorando del Departamento de Derecho Civil de la UNED

Resumen: La resolución del Tribunal Supremo objeto de estudio, cuya doctrina se ve corroborada por la STS 836/2013, abre la puerta a la determinación de la doble maternidad por naturaleza resultante de la aplicación de técnicas de reproducción asistida a través del ejercicio de la acción de reclamación de la filiación matrimonial por posesión de estado por parte de la cónyuge o excónyuge no gestante, no obstante la ausencia de la prestación del consentimiento por ésta que a tales efectos formalmente prescribe el art. 7.3 de la Ley 14/2006, sobre técnicas de reproducción humana asistida, juzgándose suficiente para esa declaración judicial de filiación materna a favor de la esposa de la mujer gestante, en consecuencia con la prevalencia de la voluntad en la fijación de la filiación en este ámbito, la mera concurrencia material del consentimiento de la misma para la aplicación de la técnica reproductiva, que podrá acreditarse por cualquier medio admitido en Derecho, modulándose, en cualquier caso, el alcance o 
virtualidad de esa voluntad de ser madre de conformidad con el principio del interés superior del menor.

Abstract: The High Court's decision under study, whose doctrine is corroborated by the STS $836 / 2013$, opens the door to determining natural double maternity resulting from the application of assisted reproduction techniques through the exercise of action of claiming marital filiation for possession of status by the non-pregnant spouse or former spouse, nevertheless the absence of the provision of consent from the same which for such effects the article 7.3 from Law $14 / 2006$, on assisted human reproduction techniques, formally prescribes, judging it sufficient for the judicial declaration of the maternal filiation in favour of the non-pregnant wife, accordingly with the prevalence of the wish to establish filiation in this area, the mere material concurrency of consent by the same to the use of the reproductive technique, which can be accredited by any means admitted by law, being modulated, in any case, the extent or effect of that wish to be a mother in accordance with the principle of the best interests of the child.

Palabras clave: REPRODUCCIÓN ASISTIDA, DOBLE MATERNIDAD, FILIACIÓN, CONSENTIMIENTO, POSESIÓN DE ESTADO, INTERÉS SUPERIOR DEL MENOR.

Keywords: ASSISTED REPRODUCTION, DOUBLE MATERNITY, FILIATION, CONSENT, POSSESSION OF STATUS, BEST INTERESTS OF THE CHILD.

Recepción original: 09/06/2014

Aceptación original: 10/07/2014

Sumario: I. El supuesto de hecho litigioso: reclamación de la filiación materna matrimonial por posesión de estado por la cónyuge no gestante respecto de dos menores nacidas mediante fecundación in vitro de la progenitora biológica. II. La exigencia de consentimiento a la utilización de técnicas de reproducción asistida en orden a la determinación legal de la filiación paterna del nacido. III. La reclamación de la filiación matrimonial materna por posesión de estado como cauce adicional para el establecimiento de la doble maternidad legal. IV. Uniones de hecho de mujeres y reclamación de la filiación extramatrimonial derivada de la utilización de técnicas de reproducción asistida. V. Conclusión. VI. Bibliografía. 


\section{EL SUPUESTO DE HECHO LITIGIOSO: RECLAMACIÓN DE LA FILIACIÓN MATERNA MATRIMONIAL POR POSESIÓN DE ESTADO POR LA CÓNYUGE NO GESTANTE RESPECTO DE DOS MENORES NACIDAS MEDIANTE FECUNDACIÓN IN VITRO DE LA PROGENITORA BIOLÓGICA}

El caso analizado en la sentencia del Tribunal Supremo objeto del presente estudio consiste en una acción de reclamación de la filiación matrimonial por posesión de estado, articulada por la cónyuge no gestante contra la madre biológica, respecto de dos menores nacidas, en fecha 14 de diciembre de 2007, mediante la fecundación in vitro de la segunda, habiendo prestado ambas litigantes, quienes contrajeron matrimonio en fecha 3 de agosto de 2007, consentimiento ante el centro sanitario para la práctica de la técnica de reproducción asistida reiterada el día 16 de marzo de 2007, por la que, sustancialmente, se instaba que se declarara judicialmente que las dos menores aludidas eran también hijas de la accionante, rectificándose la inscripción de nacimiento de aquéllas, a efectos de que se haga constar la filiación respecto de la demandante y de que, en consecuencia, constaran como apellidos de las mismas los de la actora y la interpelada ${ }^{1}$.

Las menores a las que se refiere la acción judicial ejercitada en la instancia habían sido inscritas en el Registro Civil solo con la filiación

${ }^{1}$ Por lo que respecta a la legitimación activa para el ejercicio de la acción de reclamación de la filiación existiendo posesión de estado, no controvertida en el supuesto que nos ocupa, Francisco RIVERO HERNÁNDEZ [en RAMS ALBESA, Joaquín (coord.) y MORENO FLÓREZ, Rosa María (coord. adjunta), Comentarios al Código Civil, II, Vol. 2. ', José María Bosch, editor, Barcelona, 2000, págs. 1313-1314] considera que lo que indujo al legislador a adoptar una fórmula tan amplia (cualquier persona con interés legítimo) fue la intención de facilitar el ejercicio de la acción de reclamación, con la finalidad de potenciar la coincidencia de la filiación aparente con la real. Censura este autor que el art. $131 \mathrm{CC}$ le otorgue un valor excesivo a la posesión de estado, puesto que no siempre esa realidad social se corresponde con la realidad biológica. Para el citado civilista el interés ha de ser protegible jurídicamente (legítimo) cualquiera que sea su naturaleza (material o moral) y actual, concluyendo que el hijo y los progenitores, éstos no solo para reclamar su propia paternidad o maternidad sino también la determinación de la filiación respecto del otro progenitor, tienen un interés legítimo incuestionable. Proponiendo una exégesis extensiva de la expresión legal, Carlos LASARTE ÁLVAREZ [en Principios de Derecho Civil, VI (Derecho de familia), 3. . ed., Marcial Pons, Madrid, 2002, pág. 330] sostiene que el legislador de 1981 ha pretendido ampliar la relevancia de la posesión de estado como situación de la que puede inferirse la filiación y, por ello, ha ampliado la legitimación activa para el ejercicio de las acciones de filiación. Por su parte, Román GARCÍA VARELA [en SIERRA GIL DE LA CUESTA, Ignacio (coord.), Comentario del Código Civil, Tomo 2 (Arts. 90 al 332), Ed. Bosch, Barcelona, 2000, pág. 335] señala que tienen legitimación activa los propios interesados (padres e hijo) o sus herederos o quien pueda acreditar un interés aceptable, material o moral. 
materna y con los apellidos de la madre en el orden en que esta última los ostenta, iniciándose por la progenitora el pertinente expediente de rectificación de error de las inscripciones registrales de las menores practicadas, con la finalidad de que se rectificara el error existente en cuanto al estado civil de la madre biológica, que no era el de soltera, sino de casada, y, asimismo, con el objeto de que se identificara a la entonces cónyuge (luego demandante) a los efectos de patria potestad y de la designación de su apellido, expediente que concluye por auto de fecha 5 de marzo de 2008, en el que se acuerda una rectificación parcial atinente al estado civil de la progenitora, desestimándose el resto de pedimentos deducidos, interponiéndose recurso de apelación, en cuanto a la parte denegada, contra esa resolución, que fue rechazado por la DGRN en fecha 26 de noviembre de $2008^{2}$. Finalmente, en junio del año 2009 , se produce la ruptura de la relación entre demandante y accionada, con cese de la convivencia, formulando esta última demanda de divorcio.

La sentencia dictada, en primera instancia, en fecha 11 de abril de 2011, por el Juzgado de Primera Instancia n. ${ }^{\circ} 7$ de Santa Cruz de Tenerife, convalidada ulteriormente en apelación y casación, estimó íntegramente la demanda formulada por la cónyuge de la progenitora biológica.

${ }^{2}$ La DGRN, en su Resolución (8. ${ }^{a}$ ) de 26 de noviembre de 2008, fundamenta la desestimación de la impugnación de la madre biológica atendiendo al tenor del art. 7.3 de la Ley 14/2006, de 26 de mayo, sobre técnicas de reproducción humana asistida -LTRHA-, introducido por la Disposición adicional primera de la Ley 3/2007, de 15 de marzo, reguladora de la rectificación registral de la mención relativa al sexo de las personas, precepto que dispone que «cuando la mujer estuviere casada, y no separada legalmente o de hecho, con otra mujer, esta última podrá manifestar ante el Encargado del Registro Civil del domicilio conyugal, que consiente en que cuando nazca el hijo de su cónyuge, se determine a su favor la filiación respecto del nacido». Colige la DGRN que "según resulta del precepto transcrito, la manifestación ha de hacerse antes de que nazca el hijo, y no hay constancia en el presente caso de que en el momento adecuado se formulase dicha manifestación, por lo que al ser inscritas las nacidas con la filiación de la madre biológica, no se produjo el error denunciado». Sostiene la Resolución aducida que, si bien se ha admitido la filiación de la cónyuge no gestante en supuestos en que el hijo había nacido antes de la entrada en vigor del artículo aludido y la manifestación se había verificado ulteriormente, aplicándose analógicamente la Disposición transitoria primera del CC en su redacción originaria (cfr., a título de ejemplo, la RDGRN (4. ${ }^{a}$ ) de 14 de octubre de 2008), en el caso planteado el nacimiento de las menores acaeció, no bajo la vigencia de la legislación anterior a la modificación antes expresada, sino estando vigente la norma actual, en orden a lo que no hay razón para que la manifestación sobre la filiación de la cónyuge no gestante no se hubiera hecho con carácter previo al nacimiento, concluyéndose que «la interesada sólo podrá obtener lo que ahora ha pretendido por la vía inadecuada de la rectificación de errores a través del instituto de la adopción». 
El órgano judicial a quo, en su FD $2 .^{\circ}$, viene a razonar la viabilidad del ejercicio de las acciones de reclamación de la filiación en el supuesto de matrimonios de mujeres, no obstante las lagunas legales que dimanan de la reforma del $\mathrm{CC}$ en materia de derecho a contraer matrimonio $^{3}$, que no modifica los preceptos sustantivos de ese cuerpo legal atinentes a la filiación, aduciendo, en esencia, en primer término, que los hijos de matrimonios de personas de distinto sexo no pueden tener mejor trato en derecho que los hijos de matrimonios homosexuales, impidiendo que sus progenitores o ellos mismos ejerciten las oportunas acciones de impugnación o reclamación de la filiación. En segundo lugar, invoca la resolución judicial de primera instancia que, en tanto en cuanto el art. 7.3 LTRHA autoriza que, simplemente, cuando la mujer estuviere casada con otra mujer, con el cumplimiento del mero trámite formal de la manifestación ante el Encargado del Registro Civil de que consiente que, cuando nazca el hijo de su cónyuge, se determine a su favor la filiación respecto del nasciturus, filiación que, al no ser adoptiva, debe reputarse por naturaleza, en mayor medida debe autorizarse el ejercicio de las acciones de filiación una vez acreditado adecuadamente el voluntario consentimiento para la técnica de reproducción asistida y la voluntad concorde de las partes de concebir un hijo. Finalmente, se alegan por la sentencia, en apoyo de la posición que sostiene, los artículos 14 de la Constitución Española, relativo al principio de igualdad, y 44 del CC, precepto éste que, en su apartado segundo, atribuye los mismos efectos al matrimonio cuanto ambos contrayentes sean del mismo o de diferente sexo.

De este modo, el Juzgado de Primera Instancia acoge las pretensiones de la actora porque infiere que la posesión de estado de la filiación se evidencia a partir del momento en que aquélla consiente la fecundación in vitro de la interpelada, acreditándose con actos propios y concluyentes de la accionada, coetáneos y posteriores al nacimiento de las menores, que van directa y expresamente dirigidos a que éstas figuren como hijas de la demandante (en este sentido, se reseña que el matrimonio de las partes se produce cuando la madre biológica tiene un embarazo de cinco meses y que ésta inicia el expediente registral de rectificación de error antes señalado, impugnando ante la DGRN la resolución denegatoria parcial) ${ }^{4}$, posesión de estado que, por lo demás,

${ }^{3}$ Ley 13/2005, de 1 de julio, por la que se modifica el Código Civil en materia de derecho a contraer matrimonio.

${ }^{4}$ Sobre el alcance de la doctrina de los actos propios, dice la STS de 30 de enero de 1999 (RJ 1999, 10) que "para poder estimar que se ha infringido la doctrina de los actos propios, que encuentra su apoyo legal en el artículo 7.1 del Código Civil, ha de haberse probado quebranto del deber de coherencia en los comportamientos, debiendo concurrir en los actos propios condición de ser inequívocos, en el sentido de crear, defi- 
deriva de las actuaciones judiciales llevadas a cabo por la cónyuge no gestante, dirigidas siempre, según se dice, a mantener el contacto con las menores (así, medidas provisionales previas, con petición de la fijación de un régimen de visitas, o autos de adopción), junto al hecho de que, durante un año, hasta que se produce la ruptura de la pareja, la actora comparte su vida con esas menores en calidad de madre ${ }^{5}$.

Por su parte, la sentencia dictada en la alzada, que desestima el recurso de apelación interpuesto por la progenitora biológica, confirmando íntegramente la resolución atacada, hace suya la argumentación de ésta, previamente expresada, rechazando que el hecho de que el mismo órgano judicial de instancia hubiera denegado la inscripción como madre de la recurrente (en virtud del ya indicado auto de 5 de marzo de 2008) implique una vulneración del derecho a la tutela judicial efectiva, por infracción del derecho a la motivación de las resoluciones judiciales, toda vez que se trató de una resolución dictada en un expediente gubernativo de simple rectificación de errores, con la restricción propia del objeto inherente a los expedientes de esa naturaleza, que se agota en vía administrativa con la resolución de la DGRN, como aconteció, no teniendo, por lo tanto, efectos de cosa juzgada material, pudiendo someterse, en consecuencia, la cuestión al conocimiento judicial a través del procedimiento que corresponda ${ }^{6}$.

nir, fijar, modificar o extinguir, sin ninguna duda, una precisada relación jurídica afectante a su autor, ocasionando incompatibilidad o contradicción entre la conducta precedente y la actual (Sentencias de 10-6 y 17-12-1994 (RJ 1994, 5225 y 9428), 30-10-1995 (RJ 1995, 7851) y 24-6-1996 (RJ 1996, 4846)».

${ }^{5}$ Aun cuando, atendiendo a la indisponibilidad del estado civil, no puede pretenderse una aplicación incondicionada de la doctrina de los actos propios para propiciar o basar una estimación de la acción de reclamación de la filiación que se ejercita, lo cierto es que, tal como se alega en todas las resoluciones dictadas, en ambas instancias y por el TS, parece absolutamente palmaria la concurrencia de una quiebra de la precisa concordancia entre la conducta previa de la accionada, quien inicia un expediente de rectificación de error de las inscripciones registrales de nacimiento de sus hijas, con la finalidad de que se rectificara el error en su estado civil y, asimismo, para que se identificara a la actora a efectos de patria potestad y designación de su apellido, impugnando, por lo demás, el auto judicial por el que se denegaba esta última petición, y su posición procesal posterior, oponiéndose a que se declare judicialmente la filiación materna de su cónyuge. En cuanto a este extremo, dice la STS 740/2013 que «los actos son claros, evidentes y reiterados, incluso los que pretenden elevarse a la categoría de "propios", pues una cosa es que se deban atender con cautela en acciones legalmente previstas para la protección de un interés público, como es la filiación, y otra distinta que no puedan servir como una manifestación complementaria de esta posesión de estado a partir de una acreditada relación de hecho y de derecho entre las partes que se inició con la adopción de una hija nacida con carácter previo al matrimonio, que siguió con el matrimonio, en el seno del cual nacieron las dos hijas, y que concluyó, por ahora, con el posterior divorcio (...)» (FD 3. ${ }^{\circ} 6$ ).

${ }^{6}$ Afirma la sentencia de la AP de Santa Cruz de Tenerife -Sección 1. a - de 24 de octubre de 2011 (Rollo 499/2011) que "por tal razón, la alegación de la recurrente de 
La sentencia de la Audiencia Provincial determina que están acreditados los presupuestos fácticos de la posesión de estado de la filiación, de manera ininterrumpida, continuada y pública, por el tiempo suficiente, consistentes, con otras pruebas, testificales y documentales, incluso gráficas, en la voluntad concorde de las litigantes de que la demandada se sometiera nuevamente al procedimiento de reproducción asistida, acudiendo al centro en el que las dos, en fecha 16 de marzo de 2007, consienten con su firma la práctica de dicha técnica y que las partes contraen matrimonio el día 3 de agosto de 2007, naciendo las menores en fecha 14 de diciembre de $2007^{7}$.

Asimismo, como luego asumirá la sentencia del TS, el órgano ad quem dice que "hay un hecho que supera la prueba de la posesión de estado tradicionalmente considerada en orden a la determinación de la filiación y que exime incluso del juego de la presunción judicial, cual es la prestación del consentimiento para la práctica de la técnica de reproducción asistida, de particular significación porque constituye la voluntad libre y manifestada por ambas litigantes del deseo de ser progenitoras mediante consentimiento expreso, hasta el punto de que en casos como éste dicho consentimiento debe ser apreciado aunque la posesión de estado hubiera sido escasa o no suficientemente acreditada como de ordinario se exige» ${ }^{8}$.

La STS 740/2013, finalmente, según se desarrollará más adelante, acepta la tesis de la probada existencia de la posesión de estado de la filiación matrimonial por parte de la interpelante no gestante, susten-

que se vulnera la prohibición del art. 131, párrafo segundo, del Código Civil, es errónea, por el contrario, es precisamente en el procedimiento jurisdiccional correspondiente, conforme dispone el art. 92 de la Ley del Registro Civil, como se ha de rectificar la inscripción registral previa que, evidentemente, es contradictoria con la que se declara en el procedimiento judicial, lo que sucede siempre que se reclama una filiación que contradice la inscrita, con la única excepción de prohibición establecida en el art. 764,2 de la Ley de Enjuiciamiento Civil, justamente si la determinación de la filiación es contradictoria con otra que hubiese sido establecida también por sentencia firme» (FD 5.²).

${ }^{7}$ Añade la resolución que la determinación común de las litigantes para tener un hijo puede inferirse, igualmente, al amparo del art. 386.1 LEC, por vía de presunción judicial, "puesto que no tiene otro sentido que las niñas se conciben constante la relación, después de otra decisión anterior de la que nació Cándida, mientras convivían en la misma vivienda» (FD 6. ${ }^{\circ}$ ).

${ }^{8}$ En este punto, argumenta la AP que «seguramente por esta razón la Ley 14/2006, de 26 de mayo, sobre técnicas de reproducción humana asistida, en su art. 7, apartado segundo (quiere decirse art. 8.2), prescribe que "se considera escrito indubitado a los efectos previstos en el art. 49 de la Ley del Registro Civil el documento extendido ante el centro o servicio autorizado en el que se refleje el consentimiento a la fecundación con contribución de donante prestado por varón no casado con anterioridad a la utilización de las técnicas. Queda a salvo la reclamación judicial de paternidad». La norma es imperativa» (FD 6. ${ }^{\circ}$ ). 
tada en la prueba practicada, e, incidiendo en la absoluta equiparación normativa de los matrimonios contraídos por personas homosexuales y heterosexuales, derivada de la reforma introducida por la antecitada Ley 13/2005, avala que el voluntario consentimiento ante la clínica para la utilización de la técnica de reproducción asistida y la voluntad de las partes de concebir un hijo posibilitarían, aún en defecto de una acreditación suficiente de la posesión de estado, la declaración judicial de la filiación materna a través del ejercicio de la acción de reclamación de la filiación, invocando, por vía analógica, lo dispuesto en el art. 8.2 LTRHA, transmutándose, en la práctica, ese previo consentimiento ante el centro sanitario, no exigido en precepto alguno, en una suerte de título o vía de atribución de la maternidad a la cónyuge no gestante, no obstante la inexistencia de la manifestación formal de la misma ante el Encargado del Registro Civil de que consentía en que cuando naciera el hijo -hijas, en este supuesto- de su cónyuge se determinara a su favor la filiación respecto de éste, que, como ya hemos significado, impone el art. 7.3 LTRHA, omisión que, en cualquier caso, motivó la denegación de la inscripción de la filiación materna de la actora en el litigio, lo que, conforme se ha referido ut supra, fue confirmado por la DGRN, y que no impide que el Alto Tribunal considere que, desde una perspectiva material, esa acreditada voluntad concurrente de la madre biológica y de la mujer no gestante ante la clínica para la realización de la fecundación in vitro permite inferir la concurrencia de los requisitos exigidos legalmente para la determinación de la maternidad de la última, aunque, en un plano formal, no se verifique el consentimiento de la demandante ante el Encargado del Registro Civil, invocándose el interés de las menores y la unidad y estabilidad familiar como parámetros a considerar para la fijación de la filiación? .

\footnotetext{
${ }^{9}$ Respecto al juego de la autonomía de la voluntad en materia de filiación, Francisco RIVERO HERNÂNDEZ [en «Los reconocimientos de complacencia (Con ocasión de unas sentencias recientes)», Anuario de Derecho Civil, núm. LVIII-3, julio 2005, pág. 1054] infiere que la autonomía de la voluntad es particularmente adecuada a las relaciones jurídicas e intereses disponibles, pero poco apta en el ámbito de la filiación, habida cuenta de la indisponibilidad de ésta y del estado civil, así como de la cualidad personal del hijo, vinculada de modo inherente a valores y derechos fundamentales de la persona. A su vez, Blanca GÓMEZ BENGOECHEA (en Derecho a la identidad y filiación, Ed. Dykinson, Madrid, 2007, págs. 103-104) aboga por un equilibrio entre la concepción realista de la filiación (en la que prima el vínculo biológico) y la concepción formalista (que da mayor relevancia a los vínculos afectivos, teniendo en cuenta, como criterio fundamental para la determinación de la filiación, la voluntad del padre o madre de asumir la paternidad o maternidad), que, con frecuencia, aparecen combinadas en las legislaciones de los distintos Estados. También realza la virtualidad de la voluntad de ser progenitor Aurelia María ROMERO COLOMA (en Identidad genética frente a intimidad y pruebas de paternidad, J. M. Bosch, editor, Barcelona, 2009, pág. 90), quien alude a que las técnicas de reproducción humana asistida demuestran que la filiación es un concepto social y cultural más que biológico, significando que la
} 
Esta inferencia de la STS que se estudia, que no es la razón fundamental por la que se acoge la acción de reclamación de la filiación matrimonial ejercitada por la demandante, dado que lo que motiva la estimación de la demanda y las sucesivas confirmaciones (en grado de apelación y casación) de la resolución del órgano judicial a quo es la existencia de posesión de estado de la filiación matrimonial, convenientemente probada en el proceso judicial seguido ante el JPI n. ${ }^{\circ} 7$ de Santa Cruz de Tenerife, abocaría a la mujer casada no gestante, que no haya hecho la pertinente manifestación ante el Encargado del Registro Civil ex art. 7.3 LTRHA, ante la segura negativa registral a inscribir su filiación, a recurrir a la vía judicial para impetrar la declaración judicial de la filiación del nacido a su favor.

La doctrina contenida en la STS 740/2013 se ve ratificada, esencialmente, en la STS 836/2013, de 15 de enero de 2014, dictada por el Pleno de la Sala de lo Civil del Tribunal Supremo, que, en un supuesto en el que por una mujer se ejercita una acción de reclamación de la filiación no matrimonial por posesión de estado respecto del hijo nacido, mediante técnica de reproducción asistida con material genético de donante anónimo, durante la relación de la misma con otra mujer, estimando el recurso de casación articulado por la actora, casa y anula la SAP de Toledo de 17 de enero de 2012, que había revocado la sentencia de primera instancia, resolución que, a su vez, declaró la filiación materna de la conviviente no gestante, y que se ve confirmada en casación ${ }^{10}$.

\section{LA EXIGENCIA DE CONSENTIMIENTO A LA UTILIZACIÓN DE TÉCNICAS DE REPRODUCCIÓN ASISTIDA EN ORDEN A LA DETERMINACIÓN LEGAL DE LA FILIACIÓN PATERNA DEL NACIDO}

La filiación derivada de las técnicas de reproducción asistida, no expresamente regulada en el CC, es, propiamente, una nueva forma de filiación, asimilable a la filiación por naturaleza por lo que respecta a sus efectos, pero disímil de la misma en cuanto que vinculada

doctrina habla de una verdad social, vital o sociológica, diversa de la biológica, y fundamentada, más que en el dato genético, en la voluntad y la responsabilidad.

${ }^{10}$ Expresa el TS en esta resolución que «los consentimientos prestados con ocasión del empleo de las técnicas de reproducción asistida, claramente acreditados de los hechos obrantes y que llevó a la madre biológica a poner como segundo nombre del niño el primer apellido de su pareja, como antecedente o causa de la filiación reclamada, integran y refuerzan la posesión de estado de la mujer homosexual, tanto en el plano de su función legitimadora del ejercicio de la acción, como en su faceta de medio de prueba de la filiación reclamada» (FD 2. 3 in fine). 
esencialmente al consentimiento prestado a la utilización de la técnica reproductiva ${ }^{11}$, en la que la primacía del elemento volitivo sobre el biológico o genético viene a distorsionar el concepto tradicional de filiación, anclado al principio de veracidad biológica, que inspiró la reforma de aquel cuerpo legal ${ }^{12}$, disgregándose o disociándose, así, los conceptos de filiación jurídica y biológica ${ }^{13}$.

${ }^{11}$ Como indica la STS 740/2013, «en el régimen de filiación en la aplicación de estas técnicas, el lugar del padre como verdad biológica a que se refiere el Código Civil, lo sustituye la ley por la voluntad de quien desea ser progenitor. Se posibilita, por tanto, la coexistencia de dos filiaciones a favor de personas del mismo sexo: una filiación materna biológica y una filiación no basada en la realidad biológica, sino en una pura ficción legal, ambas con los mismos efectos jurídicos que la filiación por naturaleza, una vez se hayan cumplimentado los requisitos expuestos, lo que implica que, en orden al ejercicio de una acción de reclamación de filiación, no sea necesaria la impugnación de la ya determinada, pues no es contradictoria con la que se establece por ley» (FD 3. ${ }^{\circ} 3$ ).

En consecuencia con este razonamiento, la filiación biológica (o por naturaleza) y la dimanante de la aplicación de las técnicas de reproducción asistida, emanada de la voluntad o consentimiento prestado por quien quiere ser progenitor, son dos categorías jurídicas diversas, las cuales coexisten y se equiparan en cuanto a sus efectos, que necesariamente son los inherentes a la filiación por naturaleza (art. $108 \mathrm{CC}$ ), en la que, desde una óptica conceptual, en la medida en que se construye artificiosa y formalmente a partir de la existencia de la voluntad de asumir la condición de progenitor y es, así, ajena a la verdad material, no cabe incardinar una segunda filiación materna, no obstante la dicción del precepto referido, que sólo alude a la filiación por naturaleza y la adoptiva.

En sentido contrario, en el art. 235-3 del Libro Segundo del CC de Cataluña se contempla expresamente como título de determinación de la filiación por naturaleza, con relación al padre y a la madre, el consentimiento a la fecundación asistida de la mujer.

${ }^{12}$ Se refiere al principio de veracidad biológica, que inspira la regulación del CC, la STS de 5 de diciembre de 2008, que alude a "la prevalencia de la verdad real sobre la meramente formal o presunta, conforme a los principios informadores de la Ley de 13 de mayo de 1981, y, por encima de ella, del artículo 39 de la Constitución, que asegura la protección integral de los hijos, como también lo hacen en otros ámbitos y con diferente rango otras normas (...) Conforme a tales superiores principios, la filiación se entiende como una condición personal definida, de una parte, por el hecho de ser veraz el hijo, y por otra, por el de ser verdadero progenitor; y solo desde esa concepción de la filiación, y desde la potenciación de los medios jurídicos para determinarla y lograr el acomodo de la realidad formal a la biológica, puede considerarse satisfecha la finalidad protectora del menor y, en suma, el interés también jurídicamente tutelado de la familia, lo que no empece a que del mismo modo se proteja la seguridad y estabilidad familiar y en la detentación del estado civil, sin erigir, empero, los principios informadores del sistema en regla absoluta e ilimitada».

${ }^{13}$ Eleonora LAMM (en «La importancia de la voluntad procreacional en la nueva categoría de filiación derivada de las técnicas de reproducción asistida», Revista de Bioética y Derecho, n. ${ }^{\circ} 24$, enero 2012, pág. 81) enfatiza la relevancia que adquiere el elemento volitivo en la filiación derivada de las TRA, de manera que cuando en una persona no coinciden el elemento genético, el biológico y el volitivo debe otorgarse preponderancia a este último, implicando las nuevas realidades una desbiologización y/o desgenetización de la filiación. Igualmente, Silvia TAMAYO HAYA [en "Hacia un nuevo modelo de filiación basado en la voluntad en las sociedades contemporáneas», Revista Digital de la Facultad de Derecho de la UNED, n. . 6, junio 2013, pág. 13 (edi- 
El artículo 6.3 ex LTRHA, aplicable a matrimonios heterosexuales, establece que "si la mujer estuviera casada, se precisará, además (para la utilización de las técnicas de reproducción asistida), el consentimiento de su marido, a menos que estuvieran separados legalmente o de hecho y así conste de manera fehaciente. El consentimiento del cónyuge, prestado antes de la utilización de las técnicas, deberá reunir idénticos requisitos de expresión libre, consciente y formal» ${ }^{14}$.

ción electrónica)] mantiene que en la LTRHA verdad genética y afectiva se disocian y que resulta esencial para constatar cómo se cohonestan biología y voluntad en la determinación legal de la maternidad/paternidad el consentimiento informado que han de prestar los intervinientes, particularmente las mujeres usuarias y los terceros donantes. En esta línea, Roncesvalles BARBER CÁRCAMO (en «Reproducción asistida y determinación de la filiación», $R E D U R, 8$, diciembre 2010, pág. 29), refiriéndose al principio inspirador de la determinación de la filiación en la reproducción humana asistida, resalta que la filosofía de la ley es que la voluntad de generar un nuevo ser humano a través de la aplicación de estas técnicas sustituye al dato biológico, si bien esa voluntad no tiene el carácter de título de determinación de la filiación, aplicándose los contemplados en el CC (arts. 115 y 120), introduciendo el consentimiento para aquéllas sólo modulaciones en sus efectos, con la salvedad de la previsión legal del art. 7.3 LTRHA, que ha de entenderse como un nuevo título de determinación de la filiación. Suscribe esta vinculación entre filiación y consentimiento Marina PÉREZ MONGE [en «Filiación derivada del empleo de las técnicas de reproducción asistida», en LLEDÓ YAGÜE, Francisco, y MONJE BALMASEDA, Óscar (coords.) y SÁNCHEZ SÁNCHEZ, Alicia (dir.), Los 25 temas más frecuentes en la vida práctica del derecho de familia. Tomo I (Parte sustantiva. Tema 19. Las acciones de filiación), Ed. Dykinson, Madrid, 2011, pág. 584], que define la filiación derivada de técnicas de reproducción asistida como un vínculo jurídico creado por la Ley atendiendo como criterio fundamental a la prestación del consentimiento que se exige legalmente a las personas que han solicitado la utilización de aquellas técnicas, sin que exista control administrativo o judicial previo, como, por ej., en la adopción, criterio que se acentúa con el art. 7.3 LTRHA, juzgando que por ello la determinación de la filiación es distinta de la regulada por el CC, si bien los derechos y deberes de los progenitores serán los concretados en este cuerpo legal. Finalmente, Antonia PANIZA FULLANA [en «Impugnación de la filiación extramatrimonial por la madre biológica contra la madre no gestante», Revista Doctrinal Aranzadi Civil-Mercantil, n. ${ }^{\circ}$ 4/2013, BIB 2013\1475, pág. 1 (versión electrónica)] alude a que la discordancia entre realidad biológica y jurídica en materia de filiación, ya reconocida implícitamente en la fecundación heteróloga, se evidencia totalmente en el supuesto de utilización de las técnicas de reproducción asistida cuando se trata de una pareja de dos mujeres y la inscripción de esta filiación en el Registro Civil.

${ }^{14}$ En referencia a este precepto, Carlos Manuel DÍEZ SOTO [en Comentario jurídico del artículo 6 LTRHA, en LLEDÓ YAGÜE, Francisco (dir. jurídico), MONJE BALMASEDA, Óscar (coord.) y OCHOA MARIETA, Carmen (dir. científico), Comentarios científico-jurídicos a la Ley sobre técnicas de reproducción humana asistida (Ley 14/2006, de 26 de mayo), Ed. Dykinson, Madrid, 2007, pág. 110] advierte que la literalidad del precepto, que habla de mujer casada y marido, obliga a restringir su aplicación al ámbito estricto del matrimonio heterosexual, cuando se trate de aplicar a la mujer las TRHA, no siendo exigible el consentimiento de la otra parte en los supuestos de matrimonios de mujeres, ni en las uniones no matrimoniales, cuando la receptora opte por recurrir al material reproductor procedente de donantes, si bien en tal caso no será de aplicación el art. 8,2. Ahondando en la exégesis literal de la 
El efecto legal inherente a la prestación de consentimiento a la fecundación con contribución de donante es la determinación de la filiación matrimonial del hijo nacido, conforme prescribe el art. 8.1 LTRHA $^{15}$.

Contrariamente a lo dispuesto en el precepto inicialmente reseñado, el legislador, en el supuesto de matrimonios de mujeres, no impuso la exigencia de ese consentimiento previo de la cónyuge de la usuaria para el sometimiento de ésta a las técnicas reproductivas, tal como dimana del tenor legal, lo cual, si bien, en abstracto, puede resultar difícilmente comprensible desde una perspectiva legal de equiparación del matrimonio heterosexual y homosexual, cabe inferir que obedece a que, en el primer caso, en ausencia del citado consentimiento, operaría la presunción legal de paternidad iuris tantum del art. 116 del CC, que obligaría al marido a desvirtuar, en sede judicial, la eficacia probatoria de esa presunción, de la que imperativamente se derivaría la inscripción de la filiación matrimonial del nacido, mediante el ejercicio de la oportuna acción de impugnación de esa filiación determinada legalmente, no asentada sobre la verdad biológica ${ }^{16}$.

norma, Gema TOMÁS MARTÍNEZ [en «El consentimiento en relación con la doble filiación materna matrimonial y la práctica del Registro Civil», Actualidad Civil, $\mathrm{n}^{\circ}$ 7, quincena del 1 al 15 de abril de 2010, tomo I, Ed. La Ley (La Ley 1796/2010), pág. 2 (versión electrónica)] considera que la expresión "consentimiento del cónyuge", contenida en el segundo inciso del precepto, es una alusión referencial al anterior término de marido, permitiendo abundar en esta conclusión el tenor del art. 8.1 LTRHA.

${ }^{15} \mathrm{El}$ art. 8.1 LTRHA prescribe que «ni la mujer progenitora ni el marido, cuando hayan prestado su consentimiento formal, previo y expreso a determinada fecundación con contribución de donante o donantes, podrán impugnar la filiación matrimonial del hijo nacido como consecuencia de tal fecundación». En el supuesto de que la TRA se verifique con material reproductor del marido éste será el progenitor biológico del nacido y su consentimiento tendrá por objeto el sometimiento de su cónyuge a la técnica reproductiva.

A su vez, el consentimiento a la fecundación con contribución de donante prestado por varón no casado con anterioridad a la utilización de las técnicas, formalizado en documento extendido ante el centro o servicio autorizado, previsto en el art. 8.2 LTRHA, conforme dispone el precepto, se considera como escrito indubitado a efectos de que, en defecto de reconocimiento por parte de aquél, la filiación paterna no matrimonial del nacido se determine a través del pertinente expediente gubernativo (arts. 120.2. ${ }^{\circ}$ CC y 49 LRC) o, en caso de oposición, mediante el ejercicio de la correspondiente acción de reclamación de la filiación fundamentada en el mencionado consentimiento, debiendo alcanzarse idéntica conclusión en el caso de que la técnica de reproducción asistida se opere con material reproductor del compañero de la usuaria.

${ }^{16}$ En este sentido, Francisco Javier JIMÉNEZ MUÑOZ (en La reproducción asistida y su régimen jurídico, Ed. Reus, Madrid, 2012, págs. 51 y 52) colige que, toda vez que el consentimiento del marido se exige porque tiene como consecuencia la atribución de la paternidad del nacido, no parece que en tales supuestos sea necesario el consentimiento de la cónyuge, en tanto que no cabe una atribución de la paternidad del nacido a ésta, sino solo el consentimiento por su parte a la determinación de su comaternidad. En la misma línea, Carmen CALLEJO RODRÍGUEZ (en «La llamada doble maternidad «por naturaleza»: la prevalencia de la voluntad de ser progenitora», Diario La Ley, n. ${ }^{\circ}$ 
Aun cuando la STS 740/2013 desestima el recurso de casación de la madre biológica, asumiendo la tesis o ratio decidendi de las resoluciones dictadas en ambas instancias, es decir, que existe, por parte de la actora, posesión de estado de la filiación matrimonial respecto de las menores nacidas por la fecundación in vitro de su cónyuge accionada, lo cierto es que, como razonamiento obiter dicta, viene a concluir que ese consentimiento previo conjunto de progenitora biológica y mujer no gestante ante el centro sanitario para la utilización de la técnica de reproducción asistida (prestado, en este caso, antes de contraer matrimonio), que, reiteramos, no es exigible legalmente según la LTRHA, es suficiente para la atribución de la maternidad de los nacidos a favor de ésta ${ }^{17}$, en línea, por lo demás, con lo que se determina en el art. 235-8.1

8240, 30 de enero de 2014, pág. 4) estima que la razón por la que en el matrimonio de mujeres no se exige el consentimiento a la realización de las técnicas de reproducción asistida es que en este caso no tiene operatividad la presunción de paternidad del art. 116 CC. Para Itziar ALKORTA IDIÁKEZ (en Regulación jurídica de la medicina reproductiva. Derecho español y comparado, Thomson-Aranzadi, 2003, pág. 239) el consentimiento del marido es indispensable cuando se empleen sus propios gametos y es, además, un elemento determinante del establecimiento de la paternidad del nacido con semen de donante, pero cuestiona la literalidad del art. 6.3 porque lo que el marido autoriza no es propiamente la inseminación de su esposa, dado que esto sólo le incumbe a ella, opinando que la previsión legal además de inadecuada era innecesaria.

Por su parte, TAMAYO HAYA (en «Hacia un nuevo modelo de filiación...», op. cit., pág. 19) opone que a través de esta manifestación (ante el Encargado del Registro Civil) se impone, de forma no razonable, un trato diferente al cónyuge de sexo femenino respecto al de sexo masculino con referencia a los hijos nacidos por técnicas de reproducción asistida utilizando material genético ajeno al matrimonio (fecundación heteróloga), infiriendo que, en la misma situación fáctica, la ley exige una carga adicional a la esposa, por cuanto que si desea que el hijo sea considerado suyo por naturaleza y nacido dentro del matrimonio precisará verificar los requisitos del art. 7.3 LTRHA.

${ }^{17}$ Reflexiona la resolución del Alto Tribunal que «este precepto -el art. 7.3 LTRHAhabilita a la mujer casada, y no separada legalmente o de hecho, con otra mujer, para manifestar ante el encargado del Registro Civil del domicilio conyugal, que consiente en que cuando nazca el hijo de su cónyuge, se determine a su favor la filiación respecto del nacido, con lo que se garantiza la igualdad entre matrimonios heterosexuales y homosexuales para cuya efectividad se exige que la manifestación se haga antes de que nazca el hijo, no en el momento de la inseminación, pues nada se dice ni se infiere del precepto, y es, además, la interpretación más acorde no solo con el hecho de que la inseminación no determina necesariamente el posterior embarazo y nacimiento del hijo de uno de los cónyuges, sino con el artículo 39 CE, que reconoce la protección integral de los hijos ante la Ley, con independencia de su filiación, y ésta no puede quedar subordinada a un requisito formal, como el del consentimiento previo ante el encargado del Registro Civil y no ante la clínica, en el que se prestó, una vez quede acreditado adecuadamente el voluntario consentimiento para la técnica de reproducción asistida y la voluntad concorde de las partes de concebir un hijo» (FD 3. ${ }^{\circ}$ ). Continúa diciendo el TS que «la remisión a las leyes civiles "salvo de las especificaciones establecidas en los tres siguientes artículos" que efectúa la Ley posibilita además el ejercicio de la acción que aquí se ejercita al amparo del artículo 131 del Código Civil, sobre posesión de estado, que constituye una causa para otorgar la filiación jurídica, aunque no exista el nexo biológico, y que en la práctica queda superada por la prestación del consentimiento para llevar a cabo la técnica de repro-

(C) UNED. Revista de Derecho UNED, núm. 15, 2014 
del libro segundo del CC de Cataluña, relativo a la persona y la familia ${ }^{18}$, satisfaciéndose, desde el punto de vista material, la exigencia de la manifestación ante el Encargado del Registro Civil que, formalmente, impone el art. 7.3 de la norma legal especial, cuya omisión no podría frustrar, así, el éxito de una eventual acción judicial de reclamación de la filiación matrimonial materna por parte de la cónyuge no gestante siempre que concurra su consentimiento precedente para la aplicación de una determinada técnica de reproducción asistida, el cual integra y refuerza la posesión de estado de la filiación por aquélla, conclusión que, aunque parece no demasiado compatible con la literalidad del texto legal, que debería ser modificado para evitar situaciones, poco acordes con el principio constitucional de igualdad y que inciden en una palmaria discriminación, como la analizada en el supuesto litigioso, concediéndose, expresamente, idéntica eficacia al consentimiento para la realización de la técnica reproductiva prestado por el varón o la mujer casada, colegimos que es respetuosa con la plena igualdad de efectos de los matrimonios heterosexuales y homosexuales y con el principio de no discriminación de los hijos por razón de filiación.

\section{LA RECLAMACIÓN DE LA FILIACIÓN MATRIMONIAL MATERNA POR POSESIÓN DE ESTADO COMO CAUCE ADICIONAL PARA EL ESTABLECIMIENTO DE LA DOBLE MATERNIDAD LEGAL}

El art. 7.1 LTRHA dispone que «la filiación de los nacidos con las técnicas de reproducción asistida se regulará por las leyes civiles, a salvo de las especificaciones establecidas en los tres siguientes artículos».

\footnotetext{
ducción asistida, porque "constituye la voluntad libre y manifestada por ambas litigantes del deseo de ser progenitoras", hasta el punto, dice la sentencia recurrida, que "dicho consentimiento debe ser apreciado aunque la posesión de estado hubiera sido escasa o no suficientemente acreditada como de ordinario se exige (...)"», aduciéndose, aparentemente, para fundamentar la virtualidad del consentimiento para la utilización de la técnica reproductiva que se propugna, la aplicabilidad, por vía analógica, de lo establecido en el art. 8.2 LTRHA, para concluir que «es evidente que la posesión de estado integra y refuerza el consentimiento prestado al amparo de esta norma a partir de la cual se crea un título de atribución de la paternidad»-FD 3. ${ }^{\circ} 5-$.

${ }^{18}$ De este modo, determina el precepto enunciado que «los hijos nacidos a consecuencia de la fecundación asistida de la mujer, practicada con el consentimiento expreso del cónyuge formalizado en un documento extendido ante un centro autorizado o en un documento público, son hijos matrimoniales del cónyuge que ha dado el consentimiento». De la misma forma, el art. 235-13.1, relativo a la determinación de la filiación no matrimonial, establece que "los hijos nacidos de la fecundación asistida de la madre son hijos del hombre o de la mujer que la ha consentido expresamente en un documento extendido ante un centro autorizado o en un documento público».
} 
De esta forma, la norma mencionada contiene una remisión directa a la regulación que en materia de filiación establece el CC, que, con las particularidades que se explicitan en los arts. 8, 9 y 10 LTRHA, deviene plenamente aplicable, relacionándose los títulos de determinación de la filiación matrimonial y no matrimonial en los arts. 115 y 120 , respectivamente.

El TS entiende que esa remisión posibilita el recurso a la acción de reclamación de la filiación por posesión de estado ${ }^{19}$, prevista en el art. $131 \mathrm{CC}$, coligiendo que aquélla «constituye una causa para otorgar la filiación jurídica, aunque no exista el nexo biológico, y que en la práctica queda superada por la prestación del consentimiento para llevar a cabo la técnica de reproducción asistida» (FD 3. $\left.{ }^{\circ} 5\right)^{20}$.

${ }^{19}$ Prescindiendo de la exigencia de consentimiento de la cónyuge o compañera de la mujer usuaria de la técnica reproductiva, también admite el establecimiento de una doble maternidad legal por posesión de estado el Código Civil de Quebec, disponiendo expresamente en su artículo 538.1 que «la filiación del niño nacido de una procreación asistida se establece, como una filiación por sangre, por el nacimiento. En ausencia de este título, la posesión constante de estado es suficiente; ésta se establece por una reunión suficiente de hechos que indican la relación de filiación entre el niño, la mujer que le dio a luz y, en su caso, la persona que ha formado, con esta mujer, el proyecto parental común (que puede estar conformado por una persona sola o pareja heterosexual u homosexual ex art. 538). Esta filiación hace nacer los mismos derechos y obligaciones que la filiación por la sangre», presumiéndose, en todo caso, ex art. 538.3, hijos de la cónyuge o compañera los nacidos a través de reproducción asistida durante la unión o dentro de los 300 días siguientes a su disolución o anulación. Cuando ambos progenitores son del sexo femenino, «los derechos y obligaciones que la ley atribuye al padre, en lo que difieren de los de la madre, se atribuyen a la madre que no dio a luz al niño» (cfr. art. 539.1). Igualmente, el art. 539 CCQ proscribe la impugnación de la filiación del niño «por la única razón de que haya nacido de un proyecto parental con procreación asistida», permitiéndose aquella impugnación a la persona casada o unida civilmente a la mujer que haya dado a luz al niño si no hay formación de un proyecto parental común o la prueba de que el niño no nace de la procreación asistida.

${ }^{20}$ En cuanto a la filiación derivada de la posesión de estado, por todas, resumiendo la doctrina judicial constante, la STS de 14 de noviembre de 1992 (RJ 1992/9403) dice que "por posesión de estado debe entenderse aquella relación del hijo con el padre o madre o ambos, en concepto de tal hijo (nomen, tractatus, fama), manifiesta por actos reiterados, de forma ininterrumpida, continuada y pública, precisándose en las SS. 4-5-1964 (RJ 1964\2201) y 20-5-1991 (RJ 1991\3714), que no debe exigirse que los actos reveladores de la posesión de estado sean muy numerosos, ni practicados absolutamente con plena publicidad, cuyo criterio resulta bien acertado, pues no cabe desconocer el relativismo que implica la cuestión, dependiendo, en cada caso, de las circunstancias concretas concurrentes, $y$, en este orden de cosas, es evidente que la posesión de estado habrá de durar cierto tiempo, variable según los casos, sin que sea incompatible con alguna interrupción, y no requiere, necesariamente, una existencia actual al momento de ser invocada, siendo suficiente su constancia en un próximo pasado».

Aduce Luis MARTÍNEZ CALCERRADA (en «La posesión de estado en la filiación», Diario La Ley, 1982, tomo 3, Id. La Ley 18281/2001, pág. 2 de la versión electrónica) que hubiera sido más ajustado que el art. 131 CC se refiriera a la filiación obtenida por la constante posesión de estado, porque ésta es una realidad fáctica de 
Con carácter general, el exclusivo consentimiento ante el Encargado del Registro Civil por parte de la cónyuge de la madre biológica, previsto en el art. 7.3 LTRHA, previo al nacimiento, concurriendo el presupuesto objetivo del matrimonio y la inexistencia de separación legal o de hecho, opera, en cualquier caso, como un nuevo título de determinación de la filiación materna de la misma respecto del hijo de la mujer gestante. Esta declaración de voluntad formal, unilateral e irrevocable ${ }^{21}$, temporáneamente emitida, cuya naturaleza jurídica no es asimilable a un reconocimiento de la filiación ${ }^{22}$, va a permitir, así, el establecimiento de esa doble maternidad legal, con la consecuente ruptura de la tradicional unidad de la maternidad, y que, cuando menos hasta la STS 740/2013 y la doctrina que emana de esta resolución, era el único cauce o vía legal para la determinación de una segunda filiación materna por naturaleza.

Hasta la adición del apartado tercero del art. 7 LTRHA por la Ley 3/2007, que, por vía de una ficción legal, configura un título de atribución de la maternidad por naturaleza a la cónyuge no gestante que dimana de la exclusiva voluntad de la misma explicitada ante el Encargado del Registro Civil, la maternidad era única, vinculada, indefectiblemente, al hecho del nacimiento, en consonancia con el principio de veracidad biológica que orienta la normativa en materia de filiación ${ }^{23}$, limitándose la posibilidad de que se determinara legalmen-

la que se deriva esa filiación, dado que la misma per se no la manifiesta, requiriendo el precepto que no se haya interrumpido o provenga de épocas pasadas.

${ }^{21}$ Reitera esta irrevocabilidad Javier NANCLARES VALLE [en «Reproducción asistida y doble maternidad por naturaleza», Revista Doctrinal Aranzadi Civil-Mercantil, n. ${ }^{\circ} 7 / 2008$, BIB 2008\578, pág. 14 (versión electrónica)], que cree que en atención a que el consentimiento otorgado por la esposa de la usuaria constituye un auténtico modo de determinación de la filiación matrimonial y, por lo tanto, de creación de un estado civil, no es posible la revocación unilateral de ese consentimiento, a lo que no obsta que no haya surgido el estado civil por no haberse producido el hecho del nacimiento en las condiciones del artículo 30 CC.

${ }^{22}$ BARBER CÁRCAMO, op. cit., pág. 30, entiende que la previsión del art. 7.3 LTRHA no puede calificarse técnicamente como un reconocimiento de filiación por ser manifiesta y evidente su falta de correspondencia con la realidad, de tal modo que se trataría de un reconocimiento nulo. Igualmente, JIMÉNEZ MUÑOZ (en La reproducción asistida y..., op. cit., pág. 66) matiza que el consentimiento de la mujer no gestante se diferencia del acto de reconocimiento en que éste se basa en la asunción de una verdad biológica, en orden a lo que podrá ser impugnado cuando no concuerde con aquélla, en tanto que la declaración de la cónyuge parte de una ficción legal no asentada en esa verdad.

${ }^{23}$ No obstante, actualmente, la tecnología reproductiva permite el establecimiento de una doble filiación materna en la que ambas mujeres estén vinculadas biológicamente con el nacido, como acontece en los supuestos de nacimientos derivados de la técnica de reproducción asistida denominada recepción de ovocitos de la pareja (método ROPA), opción que viene a complementar aquellas técnicas habituales para ac- 
te la maternidad de la mujer no gestante al instituto de la adopción (arts. 175.4 y $178.2 \mathrm{CC})^{24}$.

Con arreglo al tenor legal, no constituye un requisito para la determinación de esa doble maternidad legal que el matrimonio sea anterior al sometimiento a la técnica de reproducción asistida, debiendo referirse temporalmente la concurrencia de ese presupuesto al momento de la emisión del consentimiento, necesariamente anterior al nacimiento, de forma que la adquisición de la condición legal de progenitora no biológica puede producirse en virtud de la sola declaración de voluntad de ésta, aunque la misma no haya participado, directa o indirectamente, en el proceso decisorio de tener un hijo mediante

ceder a la maternidad en los casos de parejas de mujeres (inseminación artificial con semen de donante-IAD-, FIV con donación de semen, FIV con donación de óvulos y semen y la adopción de embriones), y que consiste, básicamente, en que una de las mujeres se somete a estimulación ovárica y aporta los ovocitos, que se obtienen mediante punción ovárica y son fecundados con semen de donante, al igual que en una FIV usual, con la salvedad de que los embriones se transfieren al útero de la otra mujer, que es la que gestará al hijo, de tal manera que las dos mujeres son madres biológicas del nacido por aplicación de esta técnica, la primera en su condición de progenitora genética y la segunda como progenitora gestacional. En España esa técnica reproductiva, no relacionada en el anexo de la LTRHA, ha sido avalada, en el marco de un matrimonio de mujeres, en un informe emitido en diciembre de 2008, por la Comisión Nacional de Reproducción Humana Asistida, habiendo nacido la primera niña por aplicación de la misma en el año 2009.

${ }^{24}$ La palmaria y artificiosa desvinculación o desconexión entre filiación jurídica y biológica ínsita a la admisión de la doble maternidad legal derivada de las TRA es destacada por la doctrina científica. Así, Esther FARNÓS AMORÓS (en Consentimiento a la reproducción asistida. Crisis de pareja y disposición de embriones, Atelier, Barcelona, 2011, págs. 106 y 107), aludiendo a que el art. 7.3 LTRHA implica un paso adelante en la consolidación de la ficción jurídica inherente a la filiación derivada de la fecundación asistida heteróloga, consagrando la voluntad, exteriorizada a través de los consentimientos exigidos, como criterio básico para determinar la filiación resultante de las TRA, arguye que esa norma constituye el caso más evidente de disociación entre filiación jurídica y biológica en la LTRHA, de forma que, al permitir que se determine la filiación respecto de dos personas que no pueden ostentar simultáneamente ningún vínculo genético con el nacido, "el precepto convierte la voluntad en el origen de la maternidad». Por su parte, BARBER CÁRCAMO (en «Reproducción asistida...», cit., pág. 30) concluye que "en realidad, la introducción en nuestro Derecho de la doble maternidad por naturaleza, contraria a su unidad natural y a toda la regulación del Código sobre la filiación (como muestra, un botón: art. 113.2 Cc), es tan artificial y difícil de encajar en nuestro sistema, por ajena a cualquiera de sus principios, que no resiste el mínimo análisis de técnica jurídica».

La posibilidad de establecer una doble filiación materna a partir del consentimiento se contempla, entre otros ordenamientos, en los arts. 43 y 44 de la Human Fertilisation and Embriology Act (2008) del Reino Unido, en la Parte 14 (que modifica la Status of Children Act de 1974) de la Assisted Reproductive Treatment Act 2008 (No 76 of 2008) del estado australiano de Victoria o en la Children and Parents Code (SFS 1949:381) de Suecia. Sobre este particular, cfr. FARNÓS AMORÓS, op. cit., págs. 112-117. 
la aplicación de la oportuna técnica de reproducción, lo que no se exige en la norma, como hemos visto, sin intervención, en suma, de la cónyuge gestante en ese trámite, quien no dispondrá de instrumento jurídico alguno para enervar la eficacia de ese consentimiento y a la que, en cualquier caso, se le impondría legalmente esa doble filiación por naturaleza ${ }^{25}$.

A partir de la STS 740/2013 y la ulterior STS 836/2013, y la doctrina que emana de las mismas sobre la suficiencia de la voluntad de ser progenitora que deriva del consentimiento de la cónyuge de la usuaria para el sometimiento de ésta a la técnica de reproducción asistida,

${ }^{25}$ En relación con el art. 7.3 LTRHA, Ana DÍAZ MARTÍNEZ [en «Acción de reclamación de filiación ejercitada por la mujer que no fue la madre gestante: nuevo paso en la doble maternidad derivada de reproducción asistida», Revista Doctrinal Aranzadi Civil-Mercantil, núm. 10/2014, BIB 2014\244, págs. 2 y 3 (versión electrónica)] incide en que implica admitir que la filiación en reproducción asistida tiene un importante componente volitivo, que carece de sustrato biológico y a la que deben aplicarse los mismos criterios de estabilidad e irrevocabilidad en interés del menor, lo que impide ulteriores impugnaciones basadas tan solo en el principio de veracidad biológica. En contra, asimismo, de la impugnabilidad de la filiación materna fijada ex art. 7.3 LTRHA, y proponiendo la aplicación extensiva del art. 8.1 de la norma a los casos de inseminación de mujer unida en matrimonio a otra mujer, VERDERA IZQUIERDO, Beatriz [en «La Ley de reproducción asistida y el matrimonio homosexual. La doble maternidad», en VERDERA IZQUIERDO (dir. y coord.), El principio de igualdad ante el derecho privado: una visión multidisciplinar, Ed. Dykinson, Madrid, 2013, pág. 48]. Disiente de esta posición NANCLARES VALLE, op. cit., págs. 14-16, quien excluye que la mujer que consintió en ser determinada como madre pueda impugnar esa maternidad por inadecuación a la verdad biológica, entendiendo que lo contrario implicaría admitir una conducta abusiva, contraria a la doctrina de los actos propios y opuesta a la buena fe, pero que mantiene que el hijo tiene legitimidad impugnatoria respecto de la segunda maternidad, al no haber ningún precepto que le prive de la misma y al aplicarse lo dispuesto en los arts. 137 y 140 CC. Este civilista reconoce, además, la legitimación para interponer la acción de impugnación a la madre biológica, viable si se aplicase a los supuestos de doble maternidad el art. 137.2 CC, puesto que, en este caso, no concurre la simultaneidad en la prestación de consentimientos a la fecundación asistida que sí se da en el supuesto de matrimonio heterosexual (art. 8.1 LTRHA).

La SAP de Les Illes Balears de 5 de diciembre de 2012 (La Ley 201736/2012), en un supuesto en el que por la progenitora biológica se impugnaba la inscripción de la filiación materna del hijo de aquélla nacido mediante técnica de reproducción asistida a favor de la cónyuge de la misma, tras reconocer que existe una laguna legal respecto de la acción de impugnación de la filiación ejercitada por la mujer gestante contra la conviviente cuando aquélla ha sido determinada por el consentimiento prestado por la segunda en el oportuno expediente registral, estima la demanda porque la interpelada no prestó consentimiento formal y previo para que la actora se sometiera a la técnica de reproducción humana asistida, las litigantes no estaban casadas en el momento del nacimiento del niño y aduciendo que cuando se manifestó el consentimiento del art. 7.3 LTRHA el hijo ya había nacido, concluyendo la AP que «el consentimiento determinante de la filiación, por ausencia de los requisitos indicados, resultaba ineficaz en derecho y que el asiento registral expresivo de la doble maternidad debe ser rectificado». 
ha de aceptarse, indudablemente, la existencia de una vía legal adicional al consentimiento sobrevenido del art. 7.3 LTRHA para la declaración (judicial) de la doble maternidad por naturaleza, sin que, no solo sea ya irrelevante que no concurra la mencionada manifestación ante el Encargado del Registro Civil, declaración de voluntad imperativa que se degrada, aparentemente, a la categoría de mero requisito formal prescindible en el supuesto de que se verifique el consentimiento precedente de la esposa (o conviviente) de la mujer gestante, que no tiene que adecuarse, necesariamente, al requerimiento de formalidad del art. 6.3 LTRHA, pudiendo acreditarse por cualquier medio admitido en Derecho, con la inseguridad jurídica inherente, por tanto, a esta flexibilidad, para que ésta se someta a la pertinente técnica de reproducción, sino que, conforme resulta de la segunda resolución del TS, tampoco se requiere el presupuesto objetivo del matrimonio entre ambas mujeres.

La STS 740/2013, como posteriormente se reiterará con mayor amplitud en la STS 836/2013, invoca de forma expresa, como parámetro esencial a tener en cuenta para evaluar la viabilidad de la reclamación de la filiación materna por posesión de estado en los supuestos de aplicación de las técnicas de reproducción asistida, el principio del interés superior del menor ${ }^{26}$.

${ }^{26}$ En concreto, observa la resolución que se analiza que «en estos momentos existe un interés real, y éste no es otro que el de las niñas, y el de la unidad y estabilidad familiar entre las tres hermanas que preserve las vinculaciones conseguidas entre todas, y la discrepancia entre las litigantes debe reconducirse a su ámbito natural y jurídico, que no es otro que el de la ruptura de las relaciones personales, mediante el divorcio, que ya instaron» (FD 3. ${ }^{\circ} 6.2$ ).

La STS 836/2013 desarrolla de una manera más amplia la virtualidad del interés superior del menor en orden al ejercicio de la acción de reclamación de la filiación no matrimonial por la compañera de la progenitora biológica, entendiendo que la razón de la compatibilidad entre la figura de la posesión de estado y la normativa de las técnicas de reproducción asistida ha de referirse a "los principios que inspiran su regulación en el marco constitucional de las acciones de filiación», afirmándose que «dicha razón de compatibilidad viene informada, entre otros, por los principios constitucionales de igualdad de los hijos o de no discriminación por razón de filiación o nacimiento (artículos 14 y $39.2 \mathrm{CE}$ ), de protección de la familia, de los hijos (integral) y de las madres con independencia de su estado civil (39 CE), de dignidad de la persona y libre desarrollo de su personalidad (artículo $10 \mathrm{CE}$ ), así como por la debida ponderación, cada vez más primordial, del interés superior del menor» (FD 2. ${ }^{\circ}$ ). Añade esta resolución que "por otra parte, y como también se ha puntualizado, el curso de la acción ejercitada no escapa a la ponderación o ajuste que debe realizarse conforme al interés superior del menor y, por tanto, a las concreciones y funciones que el ordenamiento jurídico le asigna. En efecto, desde su configuración como principio constitucional, reforzado por los Textos internacionales de referencia (...), así como por el propio desarrollo de la legislación nacional, Ley Orgánica 1/1996, de 15 de enero, de Protección Jurídica del Menor, debe señalarse que, como salvaguarda de los derechos fundamentales y libre desarrollo de la personalidad del menor (STS de 5 de 
En este sentido, el favor minoris, concepto jurídico indeterminado que, con total evidencia, informa la regulación jurídica en materia de filiación ${ }^{27}$, cuya virtualidad habrá de ponderarse judicialmente en cada caso concreto, con arreglo a criterios objetivos y subjetivos, es, en último término, lo que justifica el alcance, no contemplado en el plano normativo, que se le otorga a la voluntad acreditada de la mujer no usuaria que consiente la utilización de técnicas de reproducción asistida por parte de su cónyuge a efectos de que pueda declararse la doble filiación materna por posesión de estado, homologándose, en suma, al margen de la no concurrencia formal del consentimiento sobrevenido previsto en el art. 7.3 LTRHA, que hasta ahora se erigía en el único título de determinación de esa

febrero de 2013, n. ${ }^{\circ}$ 26/2013), su proyección sobre la protección de la vida familiar alcanza, sin distinción, a las relaciones familiares con independencia, como razón obstativa, de la naturaleza matrimonial o no de la misma, o al hecho de la generación biológica tomado como principio absoluto, en sí mismo considerado, de forma que incide en la existencia del lazo de familiaridad establecido con el niño permitiendo o favoreciendo su desarrollo conforme al libre desarrollo de la personalidad del menor. A su vez, desde la pauta o función de tutela que despliega el interés superior del menor, su incidencia en los derechos y bienes jurídicos concurrentes también se manifiesta en el necesario juicio de ponderación realizado a tal efecto, de forma que en el curso de la acción de reclamación de filiación no matrimonial, que trae causa del empleo de las técnicas de reproducción asistida, el interés del menor representa un control o contrapeso para adverar el alcance del consentimiento prestado por la conviviente de la madre biológica» (FD 3. ${ }^{\circ} 2$ ).

${ }^{27}$ Sobre este concepto o standard jurídico, Francisco RIVERO HERNÁNDEZ (en El interés del menor, 2. ${ }^{\mathrm{a}}$ ed., Ed. Dykinson, Madrid, 2007, págs. 27 y 28) sostiene que el favor minoris, en un contexto que orienta la protección del menor confiriéndole, sobre todo a partir de la adolescencia, el status de persona tendencialmente autónoma, no consiste ya solamente en buscar lo mejor para él, sino en ayudarle a adquirir de manera progresiva mayor autonomía y una identidad de adulto que le habilite para que ejerza directamente derechos y libertades indeclinables, siendo el interés del menor «uno de los principios y valores emergentes del moderno Derecho de la persona $y$ de familia, que inunda todo su régimen legal, irradia energía jurídica y alcanza a otras partes de nuestro ordenamiento (procesal, penal, administrativo...)». Por su parte, Isaac RAVETLLAT BALLESTÉ (en «El interés superior del niño: concepto y delimitación del término», Revista Educatio Siglo XXI, Vol. 30, n. ${ }^{\circ}$ 2, 2012, pág. 96) define el concepto de interés del menor como la proyección en los menores de edad del problema de la protección de los derechos fundamentales en general. En lo atinente al proceso de concreción del interés del menor, Bartolomé VARGAS CABRERO [en «El Ministerio Fiscal y el principio del interés del menor», en RODRÍGUEZ TORRENTE, Jesús (editor), El menor y la familia: conflictos e implicaciones, Universidad Pontificia de Comillas, 1998, pág. 90] expone que el favor minoris, concepto jurídico relativamente indeterminado, exige una ponderación detallada de todas las circunstancias personales, familiares y sociales concurrentes, en la que no se puede operar con reglas válidas para todos los casos, sin que quepa decir de forma terminante que el interés de futuro haya de prevalecer siempre sobre el de presente, ni el moral sobre el económico, ni que la permanencia en la propia familia tenga que ser priorizada siempre respecto de la salida de la misma. 
doble filiación materna por naturaleza, una mera filiación pública y social a la filiación biológica ${ }^{28}$.

En este orden de cosas, no parece lo más deseable que ese favor filii se utilice como recurso sistemático para soslayar el incumplimiento deliberado y plenamente consciente por parte de la mujer no gestante de un requisito legal imperativo para el establecimiento de la doble filiación materna matrimonial, posibilitando, por ejemplo, una declaración judicial de filiación a favor de la misma sin su anuencia, por mucho que haya consentido la aplicación de la técnica en un momento anterior, desconociéndose, en el supuesto controvertido que nos ocupa, cuál es la razón última por la que la accionante no verificó una exigencia tan simple como la que impone el art. 7.3 LTRHA, manifestando su consentimiento ante el Encargado del Registro Civil, teniendo en cuenta que, a partir de la fecha en que las partes contraen matrimonio (3 de agosto de 2007), la demandante habría dispuesto de más de cuatro meses, toda vez que el nacimiento de las menores se produjo el día 14 de diciembre de 2007, después, por consiguiente, de la entrada en vigor del precepto reseñado en fecha 17 de marzo de 2007, para cumplir el aducido trámite registral.

Asimismo, en la medida en que la posesión de estado de la filiación por parte de la cónyuge de la madre biológica, que constituye la base para el éxito de la acción de reclamación de la filiación matrimonial por aquélla ex art. $131 \mathrm{CC}$, puede producirse en ausencia, tanto

${ }^{28}$ Entre otras múltiples normas nacionales e internacionales que se refieren al interés superior del menor, el art. 2 ex Ley Orgánica 1/1996, de 15 de enero, de protección jurídica del menor, de modificación del Código Civil y de la Ley de Enjuiciamiento Civil, dice que «en la aplicación de la presente Ley primará el interés superior de los menores sobre cualquier otro interés legítimo que pudiera concurrir», disponiendo el art. 11.2 de ese texto legal que «serán principios rectores de la actuación de los poderes públicos, los siguientes: a) La supremacía del interés del menor». Asimismo, la Observación general n. ${ }^{\circ} 14$ (2013) sobre el derecho del niño a que su interés superior sea una consideración primordial (art. 3, párrafo 1, de la Convención sobre los Derechos del Niño) aprobada por el Comité de los Derechos del Niño de la ONU (OHCHR) en su 62. ${ }^{\circ}$ período de sesiones, subraya que el interés superior del niño es un concepto triple, un derecho sustantivo, un principio jurídico interpretativo fundamental y una norma de procedimiento, indicando, en cuanto a este último aspecto, que «los Estados partes deberán explicar cómo se ha respetado este derecho en la decisión, es decir, qué se ha considerado que atendía al interés superior del niño, en qué criterios se ha basado la decisión y cómo se han ponderado los intereses del niño frente a otras consideraciones, ya se trate de cuestiones normativas generales o de casos concretos» (cfr. Párrafos 1-7), especificándose, como salvaguardias y garantías procesales para velar por el interés superior del niño, el derecho de éste a expresar su propia opinión, la determinación de los hechos, la percepción del tiempo, la intervención de profesionales cualificados, la representación letrada, argumentación jurídica, mecanismos para revisar las decisiones y la evaluación del impacto en los derechos del niño (vid. Párrafos 85-99). 
de su previo consentimiento, formalmente expresado o materialmente concurrente, a la utilización de la técnica de reproducción asistida por su cónyuge gestante, como del consentimiento sobrevenido ante el Encargado del Registro Civil ex art. 7.3 LTRHA, no es radicalmente excluible la posibilidad de que, en ese supuesto, de acreditarse la posesión de estado y la indudable voluntad de la mujer no gestante de actuar como progenitora, apreciada, de este modo, después de la aplicación de la técnica reproductiva, teniendo en cuenta el principio del favor minoris, se declarara, igualmente, la filiación materna de la cónyuge no gestante.

Finalmente, dada la preeminencia y alcance que se atribuye por el TS al consentimiento o voluntad de la mujer no gestante para la aplicación de las técnicas reproductivas en orden al establecimiento de la doble filiación materna por naturaleza, tanto matrimonial como no matrimonial, hasta el punto de que, como se ha dicho, se indica expresamente que «la posesión de estado en la práctica queda superada por la prestación del consentimiento para llevar a cabo la técnica de reproducción asistida», podría cabalmente admitirse, en consecuencia con lo que se afirma de forma literal, por cuanto que no se observan argumentos jurídicos que lo excluyan claramente, la declaración de la segunda filiación materna, aun cuando no exista posesión de estado, acreditándose en sede judicial de modo conveniente esa voluntad primigenia de ser madre, a través del ejercicio de la correspondiente acción de reclamación de la filiación, por la progenitora o el hijo, ex arts. 132 y $133 \mathrm{CC}^{29}$.

${ }^{29}$ Contrariamente, DÍAZ MARTÍNEZ (en «Acción de reclamación de filiación ejercitada por la mujer que no fue la madre gestante...», cit., pág. 9) discrepa de esta posibilidad, entendiendo que la prevalencia del elemento volitivo no permite pensar en el hipotético éxito de las acciones de reclamación de la filiación sobre la base del consentimiento al proceso reproductivo cuando no concurre la posesión de estado, afirmando que, al no estar en juego dar luz a la verdad biológica existente y no conviniendo tampoco esa solución al interés del menor, quien carecerá de un vínculo afectivo con la mujer no gestante, no parece que existen razones jurídicas suficientes para su estimación.

Por nuestra parte, insistimos en que una exégesis literal de la resolución del TS que se analiza, que asume la tesis de la sentencia dictada en la alzada en este punto, no conduce a negar categóricamente que, en ausencia de posesión de estado, pueda prosperar una acción de reclamación de la filiación materna por parte de la mujer que no gestó al nacido si concurre, formal o materialmente, y se prueba de forma conveniente en el oportuno proceso judicial, su consentimiento para que su cónyuge o compañera se someta a la técnica de reproducción asistida (recordemos la literalidad de la STS, la posesión de estado «en la práctica queda superada por la prestación del consentimiento para llevar a cabo la técnica de reproducción asistida (...) hasta el punto, dice la sentencia recurrida, que dicho consentimiento debe ser apreciado aunque la posesión de estado hubiera sido escasa o no suficientemente acreditada como de ordinario se exige»), sin que pueda argüirse que el interés del menor, cuya sola invocación parece 


\section{UNIONES DE HECHO DE MUJERES Y RECLAMACIÓN DE LA FILIACIÓN EXTRAMATRIMONIAL DERIVADA DE LA UTILIZACIÓN DE TÉCNICAS DE REPRODUCCIÓN ASISTIDA}

En principio, y más allá de la deliberada discriminación inherente al tratamiento normativo disímil respecto a las parejas de hecho heterosexuales $^{30}$, una exégesis literal del tenor del art. 7.3 LTRHA, que se refiere a mujer casada, y no separada legalmente o de hecho, conduce a concluir que, a diferencia de lo que dispone la legislación catalana, no es viable el establecimiento de una doble maternidad por naturaleza, o, más propiamente, legal, en el supuesto de uniones de hecho conformadas por mujeres ${ }^{31}$, sin perjuicio de la posibilidad de la inscripción de la filiación materna a favor de quien no es progenitora biológica a través de la adopción ${ }^{32}$.

que podrá justificar una interpretación absolutamente flexible y modulable de normas jurídicas imperativas y diáfanas, en abstracto, no es compatible con ese establecimiento de la doble filiación materna, toda vez que se reputa que siempre será más positiva para aquél, teniendo en cuenta las consecuencias jurídicas dimanantes de la determinación legal de la filiación, esta opción que el hecho de que, en su caso, la filiación (no matrimonial) sólo quede determinada respecto de la madre biológica.

${ }^{30} \mathrm{Cfr}$. art. 8.2 LTRHA.

${ }^{31}$ Así, Pilar BENAVENTE MOREDA (en «La filiación de los hijos de parejas, casadas o unidas de hecho, del mismo sexo. La situación legal y jurisprudencial actual», Anuario de Derecho Civil, tomo LXIV, fasc. I, 2011, págs. 114 y 115), partiendo de que de un análisis literal de la normativa aplicable se desprende la inviabilidad de atribuir la doble maternidad por naturaleza a dos mujeres no casadas que constituyan pareja de hecho, habida cuenta que el art. 8.2 LTRA sólo prevé la atribución de la paternidad extramatrimonial al varón no casado, sugiere que el valor del consentimiento de la compañera de la usuaria de las técnicas de reproducción asistida debería ser, en caso de admitirse, idéntico al prestado por el varón no casado. De igual manera, JIMÉNEZ MUÑOZ (en La reproducción asistida..., cit., pág. 76) remarca que la previsión del artículo 7.3 excluye a las parejas de hecho homosexuales femeninas, en las cuales, en la medida en que no procederán propiamente las vías del artículo 120 del Código Civil, que se basan en la verdad biológica, la maternidad de la usuaria vendrá determinada exclusivamente por el parto, teniendo su compañera como única posibilidad el recurso a la adopción. Por último, participa del mismo criterio LAMM (en «La importancia de la voluntad procreacional en la nueva categoría...», cit., pág. 85), quien asevera que la falta de contemplación de las parejas de mujeres no casadas es injusta porque, en el caso de una pareja heterosexual no casada, aunque con matices, es suficiente el consentimiento expresado en documento sanitario (arts. 6.3 y 8.2 LTRHA), siendo que, si es una unión de hecho homosexual, a pesar de que la situación sea idéntica, con ausencia en ambos casos de aporte de material genético, la ley, en este segundo supuesto, obliga a la otra mujer a adoptar.

${ }^{32}$ Vid. arts. 175.1 y $178.2 .2 .^{\circ} \mathrm{Cc}$.

Como constata Francisco Javier JIMÉNEZ MUÑOZ (en «La atribución de la filiación de los hijos a la esposa o compañera de la madre en las parejas de lesbianas. Un estudio de la jurisprudencia reciente», Revista sobre la infancia y la adolescencia, 6, marzo 2014, pág. 57), actualmente, en particular desde la Ley 13/2005, no existe obstáculo a la adopción sucesiva por una mujer integrante de un matrimonio o unión de 
Sin embargo, esta premisa inicial tiene que ser matizada imperativamente tras la reiterada STS 836/2013, resolución que, en contra de la proscripción del acceso a la doble maternidad legal al amparo de la LTRHA en los casos de uniones de hecho de mujeres que se deriva del tenor legal, como se ha indicado, admite expresamente la posibilidad de que, por vía de la acción de reclamación de la filiación no matrimonial por posesión de estado por la excompañera de la madre biológica, una vez acreditados los consentimientos para el empleo de las técnicas reproductivas (no formalmente expresado por la actora) y atendiendo, primordialmente, al principio del interés superior del menor $^{33}$, concepto indeterminado convertido en parámetro o criterio esencial que justificaría, en último término, la viabilidad de la acción

hecho de los hijos de su cónyuge o compañera, madre biológica o adoptiva de los menores, de la misma manera que no concurre óbice para una adopción conjunta o simultánea por ambas mujeres, «pues estas adopciones deben considerarse equiparadas en todos los sentidos a las que puedan realizar las parejas heterosexuales».

En consonancia con la inviabilidad del establecimiento de una doble maternidad legal al amparo de la LTRHA si no existe matrimonio previo al hecho del nacimiento, y la consecuente falta de concurrencia del presupuesto inicial del art. 7.3 LTRHA, la DGRN viene denegando la inscripción de la filiación materna del nacido a favor de la mujer no gestante integrante de una pareja de hecho, y, en esta línea, la RDGRN de 12 de enero de 2011 (LA LEY 279267/2011) aduce que «la incorporación de este tercer párrafo (se refiere al art. 7 ex LTRHA) trató de salir al paso de la situación previa, en la que aún partiendo del principio incuestionable de que las parejas del mismo sexo no deben ser objeto de discriminación, los efectos atribuidos a las mismas no podían llegar, en ausencia de tal reforma, al extremo de que se estableciese doblemente, por la sola declaración de las interesadas, la maternidad tanto respecto a la mujer que hubiese dado a luz como respecto de la mujer casada con ella (vid. Resolución de 5-6. ${ }^{a}$ de junio de 2006). La maternidad ha sido considerada única hasta la citada reforma en nuestro Derecho, quedando determinada por naturaleza o por adopción, resultando en el primer caso, respecto de la madre, del hecho del nacimiento, conforme al principio de veracidad biológica que inspira nuestro ordenamiento en materia de filiación». Acoge la misma argumentación la RDGRN de 28 de febrero de 2011 (LA LEY 285864/2011).

${ }^{33}$ En concreto, la STS del Pleno de la Sala Primera del TS (como ya se ha expresado previamente) apunta la compatibilidad entre la figura de la posesión de estado y la normativa de las técnicas de reproducción asistida en virtud de principios constitucionales (igualdad de los hijos, no discriminación por razón de filiación o nacimiento...), "así como por la debida ponderación, cada vez más primordial, del interés superior del menor», insistiendo en el protagonismo de los consentimientos implicados como elementos impulsores de la determinación legal de la filiación y reiterando lo ya afirmado en la STS 740/2013 respecto a que esos consentimientos «integran y refuerzan la posesión de estado de la mujer homosexual tanto en el plano de su función legitimadora del ejercicio de la acción, como en su faceta de medio de prueba de la filiación reclamada». Para el Alto Tribunal se justifica el interés legítimo de la accionante para el ejercicio de la acción, constatando la concurrencia de hechos reveladores de la posesión de estado, tal como se infiere de la STS 320/2011, relativa a un litigio entre las mismas partes, y de lo acreditado en las instancias, afirmándose que «en el curso de la acción de reclamación de filiación no matrimonial, que trae causa del empleo de las técnicas de reproducción asistida, el interés del menor representa un control 
que se ejercita, asimilando de facto uniones de hecho y matrimonios de mujeres, pueda atribuirse a la mujer no gestante la filiación materna del nacido mediante la aplicación de la técnica de reproducción asistida a la compañera de aquélla, teniendo en cuenta que la posesión de estado, más que una forma directa de acreditación de la filiación stricto sensu, constituye un medio de prueba indirecto para ese fin, de tal manera que el recurso al art. $131 \mathrm{CC}$, cuando no se verifican materialmente los requisitos que exige el art. 7.3 LTRHA, a los efectos de la atribución de esa doble maternidad o comaternidad legal en el marco de las uniones de hecho femeninas, resulta, en ausencia de una necesaria y deseable mutación legislativa que amplíe el ámbito de la norma, de difícil intelección ${ }^{34}$.

o contrapeso para adverar el alcance del consentimiento prestado por la conviviente de la madre biológica» (FD 3. ${ }^{\circ}$ ).

${ }^{34}$ En esta línea, en el voto particular discrepante formulado, por tres Magistrados, a la STS 836/2013, y que exponemos con cierta extensión por su indudable relevancia y porque juzgamos absolutamente procedente la tesis que contiene, al margen de que no se considera probado el consentimiento de la recurrente al empleo de las técnicas de reproducción asistida por su compañera, formalmente no prestado, por otra parte, y de entender que, tanto la STS de 12 de mayo de 2011, relativa a las mismas litigantes, que dispuso un régimen de visitas a favor de la ahora demandante, como la STS de 5 de diciembre de 2013, no pueden autorizar la estimación del recurso de casación, se determina que la norma especial (art. 7.3 LTRHA), que integra un régimen jurídico específico aplicable atendiendo a lo que prescribe el apartado 1 de ese precepto, opta por el requisito del matrimonio, en el que se advierte un elemento de estabilidad, para el eventual establecimiento de la relación de filiación entre el nacido y la mujer no gestante, quien tiene que contar con el previo acuerdo de la madre biológica para que se determine la filiación a su favor, afirmándose que «no tiene sentido reconocer a posteriori, ni deformando la aplicación transitoria de la norma (que no estaba vigente antes de que naciera el hijo), aquella forma de maternidad, porque no perduran en el tiempo los requisitos que hubieran justificado en su día esta determinación de la filiación si hubiera estado en vigor el art. 7.3 LRTHA»-Fundamento 6. ${ }^{\circ} 6$-. Igualmente, los Magistrados discrepantes disienten de que la posesión de estado pueda acreditar una filiación que se determina de conformidad con el art. 7.3 LTRHA, sosteniendo que "la posesión de estado no acredita por sí la filiación, sino que constituye una mera situación fáctica que permite presumir quiénes pueden ser los progenitores, sin que encuentre encaje con este nuevo título de determinación de la filiación que se basa en el mero consentimiento de la mujer casada con la madre receptora de la reproducción asistida»-Fundamento 6. ${ }^{\circ}$-, incidiendo en que "la posesión de estado no tiene, propiamente, eficacia acreditativa de la filiación, sino que constituye un medio de prueba de carácter presuntivo o indirecto, en cuanto ofrece una sólida base de hecho para apreciar la existencia de una relación biológica que constituye el objeto de las acciones judiciales de reclamación de la filiación (sentencias 13 de noviembre de 1992, 16 de mayo de 1997) y lo contrario su ausencia (sentencia de 8 de julio de 1991)», para concluir que "no cabe invocar la posesión de estado para justificar por sí, al amparo del art. 131 CC, una filiación que se determina necesariamente por el consentimiento de la mujer, cumplidos unos determinados requisitos, si por las razones que sean ese consentimiento no se prestó en su día y ahora no es posible hacerlo"-Fundamento $7 .^{\circ} 1$ y 2-. Tampoco comparten los autores del voto particular que el interés superior del menor justifique la estimación del recurso, toda vez que su invocación no puede legitimar la aplicación de las normas del or- 


\section{CONCLUSIÓN}

Con independencia de que la concordancia o vinculación mecánica de la filiación con el elemento biológico o genético es algo completamente superado en la actualidad, teniendo un papel preeminente para la fijación de la filiación en el ámbito de la tecnología reproductiva, auténtico tertium genus, igualmente disímil de una filiación adoptiva en la que el elemento volitivo también está presente de manera central (obviamente, no antes del nacimiento) y que se constituye por resolución judicial, el deseo o la probada voluntad de ser progenitor, es decir, la denominada voluntad procreacional, el recurso a la posesión de estado, que no es sino una mera situación de hecho a partir de la cual se presume o infiere la filiación, pero que no la acredita por sí misma, como fundamento para el establecimiento de la doble filiación materna derivada de las técnicas de reproducción asistida, a través del ejercicio de las acciones de reclamación de la filiación, matrimonial o no matrimonial, por la esposa o integrante de una unión de hecho femenina no gestantes, cuando concurre su consentimiento para la aplicación de aquellas técnicas y atendiendo al criterio indeterminado del interés superior del menor para justificar la compatibilidad del CC y la LTRHA y ponderar o modular la suficiencia de esa voluntad en orden a la determinación de la filiación, habida cuenta que la norma imperativa especial que regula la materia exige para que pueda determinarse legalmente esa segunda filiación materna la concurrencia del consentimiento sobrevenido manifestado de manera formal por la mujer casada no gestante ante el Encargado del Registro Civil ex art. 7.3 LTRHA, crea inseguridad jurídica, dado que se ignora si el exclusivo consentimiento sin posesión de estado va a ser suficiente para el éxito de la acción judicial de reclamación por parte de los sujetos legitimados o si, por el contrario, la simple concurrencia de aquella situación fáctica, aún sin ese presupuesto volitivo precedente, podrá fundamentar, asimismo, una declaración judicial de maternidad, por mucho que se invoquen principios constitucionales para verificar exégesis cuya conciliación con lo normado no es sencilla, con la segura negativa registral a inscribir la filiación de la mujer no gestante, en ausencia de una necesaria modificación legisla-

\footnotetext{
denamiento jurídico en cualquier sentido, "sino en aquél en que de verás se evidencie que opera en beneficio de dicho menor, pues lo contrario sería un mero ejercicio de voluntarismo jurídico", afirmando que, habida cuenta de las circunstancias traumáticas de la ruptura entre las litigantes y el hecho de que podrían haber contraído matrimonio antes de la misma, "la estimación del recurso de casación de la demandante satisface, no el interés superior del menor, sino la "aspiración de ser madre" de la demandante, "cuya efectividad depende, precisamente, del éxito de la acción entablada" (FJ 2. ${ }^{\circ}-4$ de la sentencia de la que se disiente)»-Fundamento $8 .^{\circ} 1$ y $2-$.
} 
tiva del CC (o, en su caso, de la ley especial) que contemple, como hace la legislación catalana, el consentimiento expreso y formal a la fecundación asistida de la usuaria como título de determinación de la filiación materna matrimonial y no matrimonial.

\section{BIBLIOGRAFÍA}

ALKORTA IDIÁKEZ, Itziar, Regulación jurídica de la medicina reproductiva. Derecho español y comparado, Thomson-Aranzadi, 2003.

BARBER CÁRCAMO, Roncesvalles, «Reproducción asistida y determinación de la filiación», $R E D U R, 8$, diciembre 2010, págs. 25-37.

BENAVENTE MOREDA, Pilar, «La filiación de los hijos de parejas, casadas o unidas de hecho, del mismo sexo. La situación legal y jurisprudencial actual», Anuario de Derecho Civil, tomo LXIV, fasc. I, 2011, págs. 75-124.

CALLEJO RODRÍGUEZ, Carmen, «La llamada doble maternidad «por naturaleza»: la prevalencia de la voluntad de ser progenitora», Diario La Ley, n. ${ }^{\circ}$ 8240, 30 de enero de 2014, págs. 1-8.

DÍAZ MARTÍNEZ, Ana, «Acción de reclamación de filiación ejercitada por la mujer que no fue la madre gestante: nuevo paso en la doble maternidad derivada de reproducción asistida», Revista Doctrinal Aranzadi Civil-Mercantil, núm. 10/2014, BIB 2014\244 (versión electrónica).

DÍEZ SOTO, Carlos Manuel (Comentario jurídico del artículo 6 LTRHA), en LLEDÓ YAGÜE, Francisco (dir. jurídico), MONJE BALMASEDA, Óscar (coord.) y OCHOA MARIETA, Carmen (dir. científico), Comentarios científico-jurídicos a la Ley sobre técnicas de reproducción humana asistida (Ley 14/2006, de 26 de mayo), Ed. Dykinson, Madrid, 2007, págs. 104-110.

FARNÓS AMORÓS, Esther, Consentimiento a la reproducción asistida. Crisis de pareja y disposición de embriones, Atelier, Barcelona, 2011.

GARCÍA VARELA, Román (Comentario del art. 131), en SIERRA GIL DE LA CUESTA, Ignacio (coord.), Comentario del Código Civil, Tomo 2 (Arts. 90 al 332), Ed. Bosch, Barcelona, 2000, págs. 334-339.

GÓMEZ BENGOECHEA, Blanca, Derecho a la identidad y filiación, Ed. Dykinson, Madrid, 2007.

JIMÉNEZ MUÑOZ, Francisco Javier, La reproducción asistida y su régimen jurídico, Ed. Reus, Madrid, 2012. 
- «La atribución de la filiación de los hijos a la esposa o compañera de la madre en las parejas de lesbianas. Un estudio de la jurisprudencia reciente», Revista sobre la infancia y la adolescencia, 6, marzo 2014, págs. 51-63.

LAMM, Eleonora, «La importancia de la voluntad procreacional en la nueva categoría de filiación derivada de las técnicas de reproducción asistida», Revista de Bioética y Derecho, n. 24, enero 2012, págs. 76-91.

LASARTE ÁlVAREZ, Carlos, Principios de Derecho Civil, VI (Derecho de familia), 3. ${ }^{\mathrm{a}}$ ed., Ed. Marcial Pons, Madrid, 2002.

MARTÍNEZ CALCERRADA, Luis, «La posesión de estado en la filiación», Diario La Ley, 1982, tomo 3, Id. La Ley 18281/2001 (versión electrónica).

NANCLARES VALLE, Javier, «Reproducción asistida y doble maternidad por naturaleza», Revista Doctrinal Aranzadi Civil-Mercantil, n. ${ }^{\circ}$ 7/2008, BIB 2008\578 (versión electrónica).

PANIZA FULLANA, Antonia, «Impugnación de la filiación extramatrimonial por la madre biológica contra la madre no gestante», Revista Doctrinal Aranzadi Civil-Mercantil, n. ${ }^{\circ}$ 4/2013, BIB $2013 \backslash 1475$ (versión electrónica).

PÉREZ MONGE, Marina, «Filiación derivada del empleo de las técnicas de reproducción asistida», en LLEDÓ YAGÜE, Francisco, y MONJE BALMASEDA, Óscar (coords.), y SÁNCHEZ SÁNCHEZ, Alicia (dir.), Los 25 temas más frecuentes en la vida práctica del derecho de familia. Tomo I (Parte sustantiva. Tema 19. Las acciones de filiación), Ed. Dykinson, Madrid, 2011, págs. 578-615.

RAVETLLAT BALLESTÉ, Isaac, «El interés superior del niño: concepto y delimitación del término", Revista Educatio Siglo XXI, Vol. 30, n. ${ }^{\circ}$ 2, 2012, págs. 89-108.

RIVERO HERNÁNDEZ, Francisco, en RAMS ALBESA, Joaquín (coord.) y MORENO FLÓREZ, Rosa María (coord. adjunta), Comentarios al Código Civil, II, Vol. 2. ${ }^{\circ}$, José María Bosch, editor, Barcelona, 2000, págs. 1309-1354.

- «Los reconocimientos de complacencia (Con ocasión de unas sentencias recientes)», Anuario de Derecho Civil, núm. LVIII-3, julio 2005, págs. 1049-1114.

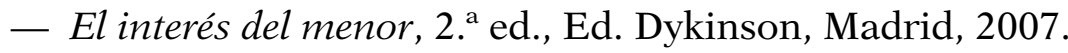

ROMERO COLOMA, Aurelia María, Identidad genética frente a intimidad y pruebas de paternidad, J. M. Bosch, editor, Barcelona, 2009. 
TAMAYO HAYA, Silvia, «Hacia un nuevo modelo de filiación basado en la voluntad en las sociedades contemporáneas», Revista Digital de la Facultad de Derecho de la UNED, n. ${ }^{\circ}$ 6, junio 2013.

TOMÁS MARTÍNEZ, Gema, «El consentimiento en relación con la doble filiación materna matrimonial y la práctica del Registro Civil», Actualidad Civil, n. ${ }^{\circ}$ 7, quincena del 1 al 15 de abril de 2010, tomo I, Ed. La Ley (La Ley 1796/2010) -versión electrónica-.

VARGAS CABRERO, Bartolomé, «El Ministerio Fiscal y el principio del interés del menor», en RODRÍGUEZ TORRENTE, Jesús (editor), El menor y la familia: conflictos e implicaciones, Universidad Pontificia de Comillas, 1998, págs. 85-98.

VERDERA IZQUIERDO, Beatriz, «La Ley de reproducción asistida y el matrimonio homosexual. La doble maternidad», en VERDERA IZQUIERDO (dir. y coord.), El principio de igualdad ante el derecho privado: una visión multidisciplinar, Ed. Dykinson, Madrid, 2013, págs. 39-54. 
